Research Paper

\title{
Screening and characterization of endophytic Bacillus and Paenibacillus strains from medicinal plant Lonicera japonica for use as potential plant growth promoters
}

\author{
Longfei Zhao ${ }^{1, *}$, Yajun $\mathrm{Xu}^{1}$, Xin-He Lai ${ }^{2, *}$, Changjuan $\mathrm{Shan}^{3}$, \\ Zhenshan Deng ${ }^{4}$, Yuliang $\mathrm{Ji}^{5}$ \\ ${ }^{1}$ Key Laboratory of Plant-Microbe Interactions of Henan, Shangqiu Normal University, PR China. \\ ${ }^{2}$ Institute of Translational Medicine, Wenzhou Medical University, PR China. \\ ${ }^{3}$ School of Science and Technology, Henan Institute of Science and Technology PR China. \\ ${ }^{4}$ College of Life Sciences, Yan'an University, PR China. \\ ${ }^{5}$ Biological and Medical Engineering Department, Shangluo University, PR China.
}

Submitted: January 13, 2014; Approved: December 28, 2014.

\begin{abstract}
A total of 48 endophytic bacteria were isolated from surface-sterilized tissues of the medicinal plant Lonicera japonica, which is grown in eastern China; six strains were selected for further study based on their potential ability to promote plant growth in vitro (siderophore and indoleacetic acid production). The bacteria were characterized by phylogenetically analyzing their 16S rRNA gene similarity, by examining their effect on the mycelial development of pathogenic fungi, by testing their potential plant growth-promoting characteristics, and by measuring wheat growth parameters after inoculation. Results showed that the number of endophytic bacteria in L. japonica varied among different tissues, but it remained relatively stable in the same tissues from four different plantation locations. Among the three endophytic strains, strains 122 and 124 both had high siderophore production, with the latter showing the highest phosphate solubilization activity $(45.6 \mathrm{mg} / \mathrm{L})$ and aminocyclopropane-1-carboxylic acid deaminase activity $(47.3 \mathrm{nmol} / \mathrm{mg} / \mathrm{h})$. Strain 170 had the highest indoleacetic acid (IAA) production $(49.2 \mathrm{mg} / \mathrm{L})$ and cellulase and pectinase activities. After inoculation, most of the six selected isolates showed a strong capacity to promote wheat growth. Compared with the controls, the increase in the shoot length, root length, fresh weight, dry weight, and chlorophyll content was most remarkable in wheat seedlings inoculated with strain 130. The positive correlation between enzyme (cellulose and pectinase) activity and inhibition rate on Fusarium oxysporum, the IAA production, and the root length of wheat seedlings inoculated with each tested endophytic strain was significant in regression analysis. Deformity of pathogenic fungal mycelia was observed under a microscope after the interaction with the endophytic isolates. Such deformity may be directly related to the production of hydrolytic bacterial enzymes (cellulose and pectinase). The six endophytic bacterial strains were identified to be Paenibacillus and Bacillus strains based on the results of $16 \mathrm{~S}$ rRNA gene sequencing analysis and their physiological and biochemical characteristics. Results indicate the promising application of endophytic bacteria to the biological control of pathogenic fungi and the improvement of wheat crop growth.
\end{abstract}

Key words: Lonicera japonica, Bacillus, Paenibacillus, plant growth-promoting characteristics, endophytic bacterium, wheat (Triticum aestivum).

Send correspondence to L. Zhao. Shangqiu Normal University, Shangqiu, 476000 Henan, PR China. E-mail: hnzhaolongfei@163.com.

*These authors contributed equally to this work. 


\section{Introduction}

Endophytes are important constituents of the plant microecosystem. These organisms have formed a mutually beneficial relationship with their host plants during longterm evolutionary processes. Endophytic bacteria reside intercellularly or intracellularly within the host tissues and do not cause visible damage or morphological changes in their hosts. Therefore, these bacteria may be more advantageous for plant survival as protection from environmental stress and microbial competition (Geetha et al., 2008). Some endophytes benefit the host plants, i.e., they increase soil porosity, produce indoleacetic acid (IAA, a phytohormone), siderophores, and antibiotic compounds, function in phosphate solubilization and nitrogen fixation, suppress phytopathogens via competition for colonization sites and nutrients, and act as antagonists of nematodes (Khan et al., 2008). Furthermore, endophytes may help symbiotic rhizobia form nodules with non-specific hosts and promote plant growth (Zhao et al., 2011). Therefore, endophytic bacteria are important microbial resources and have gradually become a multidisciplinary research hotspot in different fields, including botany, microbiology, plant protection, and plant breeding. Microorganisms associated with medicinal plants are of interest as producers of compounds responsible for plant bioactivity. A recent study has highlighted the potential use of endophytes for synthesis of bioactive compounds, promotion of plant growth, and enhanced resistance to various pathogens and drought (Miller et al., 2012a). Conceivably, endophyte-derived metabolites may be related to the observed bioactivity and beneficial health claims of the host plants in traditional Chinese medicine (TCM). As a perennial semi-evergreen winding woody liana of the genus Lonicera in Caprifoliaceae, Lonicerae japonica (commonly known as honeysuckle or Jinyinhua in Chinese) is an herb used in TCM as Flos Lonicerae; the plant is widely grown in the Henan, Hebei, and Shandong Provinces of China. Given its latent fever-clearing, antibacterial, antifungal, antiviral, and antiinflammatory effects, the herb has been prescribed to treat "fever syndrome" (a TCM term; an aspect of the common cold), febrile diseases, dysentery, carbuncles, and virulent swellings (Mphprc 2000; Li et al., 2003; Wu et al., 2007).

Bacteria has been isolated from the rhizosphere of wheat (Triticum aestivum), which is a major staple crop being cultivated worldwide and the largest annual crop (24.4 Mha, 2012) in China. These bacterial isolates mainly include Azospirillum brasilense, Pantoea agglomerans, Arthrobacter spp., Achromobacter xylosoxidans, Herbaspirillum hiltneri, Stenotrophomonas maltophilia, Pseudomonas spp., Bacillus spp., Rahnella aquatilis, Paenibacillus riograndensis, and $P$. polymyxa (Venieraki et al., 2011). Bacillus and Paenibacillus strains are prominent members of the endophyte population in healthy tissues of medicinal plants and function as prolific producers of bioactive compounds, including antimicrobials, sidero- phores, and phytotoxins (Miller et al., 2012b). For example, $P$. polymyxa benefits plants by reducing disease severity, inducing defense mechanisms, promoting growth, and producing several hydrolytic enzymes ( $\beta-1,3$-glucanases and chitinases) and antifungal or antibacterial metabolites (Deng et al., 2011; Raza et al., 2009; Lai et al., 2012; Raza et al., 2009). In addition, Bacillus sp. is involved in the biosynthesis of a broad spectrum of antibiotics (e.g., surfactant lichenysin) and can effectively reduce disease incidence in diverse plant hosts by inducing systemic disease resistance (Bianco et al., 2011), forming biofilms on root surfaces and endospores, suppressing root phytopathogens, and promoting heat and desiccation tolerance by colonizing the rhizosphere (Chen et al., 2013; Liu et al., 2009).

Phytopathogens cause a variety of plant diseases and are useful model microorganisms for studying various aspects of host-pathogen interactions. Alternaria and Fusarium species can be found as pre-harvest fungal contaminants in wheat (María et al., 2013). Alternaria sp. is the predominant genus found in wheat grown in different agroecological regions, with $A$. alternata being the most prevalent species (Gonzalez et al., 1996; Broggi et al., 2007; Ramirez et al., 2005; María et al., 2013). Magnaporthe grisea causes rice blast disease, which is one of the most serious plant fungal diseases, whereas Fusarium oxysporum may cause diseases in various crops, such as rice and wheat.

The endophytes present in various plants and the antibacterial activity of endophytic fungi isolated from Flos Lonicerae have been investigated (Li et al., 2010). However, only a few studies have reported the effect of endophytic bacteria from Flos Lonicerae on phytopathogens (Xu et al., 2013), and information is limited on the use of endophytes isolated from tissues of the medicinal plant $L$. japonica in wheat production. Moreover, the role of endophytic bacteria in plant growth and their antagonistic potential against phytopathogens are unclear.

The objectives of our study were as follows: (1) to isolate and screen endophytic bacteria from tissues of the medicinal plant $L$. japonica; (2) to characterize the plant growth-promoting characteristics (PGPC) of endophytic bacteria; and (3) to detect the antifungal activities and effects of endophytic bacteria on wheat seedlings.

\section{Materials and Methods}

\section{Collection of $L$. japonica samples}

Root, stem, and leaf samples were collected from the medicinal plant $L$. japonica (traditional variety Damaohua, $2 n=18$ ) growing in four different locations in the Henan and Shandong Provinces from July 2011 to July 2012. Samples were collected during the plant's flowering and growth stages, when active metabolism facilitated plant identification. The four sampling sites were the medicinal botanical garden of Shangqiu Normal University, the Huaxian 
County of Henan Province, and the Pingyi County and Juye County of Shangdong Province. The distance between sampling sites was more than $50 \mathrm{~km}$; each sampling site included at least three subsites that were more than $1 \mathrm{~km}$ apart. From each subsite, 5 plants that were separated at least by $30 \mathrm{~m}$ were randomly chosen and uprooted. Upon collection, samples were placed in sterile bags and stored in the dark at $4{ }^{\circ} \mathrm{C}$ until further processing, usually within $24 \mathrm{~h}$ of collection.

\section{Isolation of endophytic bacteria}

Briefly, $5 \mathrm{~g}$ each of root, stem, or leaf were carefully weighed from a pooled mixture of healthy $L$. japonica plants, washed with sterile water to remove remaining soil particles and attached epiphytic bacteria, and cut into 1-2 cm small portions with sterile scissors. These portions were further surface-sterilized by sequential immersion in $95 \%$ ethanol for $30 \mathrm{~s}$ then in $5 \%$ sodium hypochlorite for 3 min before the samples were finally rinsed eight times in sterile distilled water. A total of 5 plants were used from each subsite to form a mixture sample from the same tissue, such that 15 plants were used for each site. Strain isolation was performed from a pooled replicate of the same tissue from five plants in each subsite, such that each site had three replicates. The surface-sterilized portions were placed into sterile metal mortar, ground to slurry with $0.85 \%$ sterile saline, and shaken with a vortex for $1 \mathrm{~min}$. In the stationary state, the supernatant was collected and diluted in different concentrations of the bacterial suspension. Subsequently, $100 \mu \mathrm{L}$ of each processed sample suspension was plated (with three replicates per sample) on nutrient agar (NA) plates ( $5.0 \mathrm{~g}$ peptone, $1.5 \mathrm{~g}$ yeast extract, $1.5 \mathrm{~g}$ beef extract, $5.0 \mathrm{~g} \mathrm{NaCl}, 20 \mathrm{~g}$ agar, and $1 \mathrm{~L}$ distilled water; pH 7.2) (Deng et al., 2011). The cultures were incubated at $28{ }^{\circ} \mathrm{C}$ for $3 \mathrm{~d}$. A single colony of each isolate was re-streaked on fresh plates of the same media and microscopically examined. The pure cultures were preserved on plates at $4{ }^{\circ} \mathrm{C}$ for temporary storage or in sterile vials with $30 \%(\mathrm{v} / \mathrm{v})$ glycerol for long-term storage at $-80{ }^{\circ} \mathrm{C}$.

To confirm the successful surface sterilization process, the surface sterilized portions were rolled over the NA plates or aliquots of water from the final rinse solutions. These portions were plated onto fresh NA plates and examined for contaminants. Plates with no contaminants were effectively surface sterilized and were used for the isolation of endophytes.

\section{Characterization of plant growth-promoting characteristics (PGPC) of endophytic bacteria}

\section{Examination of siderophore production}

Bacteria were cultured in lysogeny broth (LB; $10 \mathrm{~g}$ $\mathrm{NaCl} / \mathrm{L}$ ) for $72 \mathrm{~h}$ under iron-restricted conditions. Aliquots of each bacterial culture were inoculated in plates (three plates per strain) containing agar Chrome Azurol S (CAS) and incubated at $30^{\circ} \mathrm{C}$. Plates were observed daily for $7 \mathrm{~d}$ to detect the appearance of an orange halo around the colonies (Schwyn et al., 1987). The siderophore levels produced by the isolates corresponded to the diameter of the orange halo. The presence of catechol and hydroxamate siderophores in the culture supernatants obtained from bacteria grown in iron-restricted conditions in casamino acid (CAA) medium was quantitatively determined by the colorimetric assay, as previously described (Ma et al., 2011).

\section{Phosphate solubilization}

To determine the phosphate-solubilizing activity, the isolates were cultured in triplicate in modified Pikovskayas medium ( $0.5 \%$ tricalcium phosphate) (Sundara-Rao et al., 1963) at $30{ }^{\circ} \mathrm{C}$ for $7 \mathrm{~d}$ at $200 \mathrm{rpm}$. The solubilized phosphate in the culture supernatant was quantified as described by Fiske and Subbarow (1925).

\section{Indole acetic acid (IAA) production}

IAA production was examined as previously described (Gordon et al., 1951; Inés et al., 2011). Briefly, each bacterial suspension $\left(1 \times 10^{8} \mathrm{cfu} / \mathrm{mL}\right)$ was inoculated in $10 \mathrm{~mL}$ LB broth containing L-TRYPTOPHAN $(100 \mu \mathrm{G} / \mathrm{ML})$ AND INCUBATED AT $28^{\circ} \mathrm{C}$ for $72 \mathrm{~h}$ at $200 \mathrm{rpm}$. Bacterial cells were removed by centrifugation at $8,000 \mathrm{rpm}$ for $15 \mathrm{~min}$, and the collected supernatant was incubated at room temperature in the dark for $30 \mathrm{~min}$. Pure IAA (Sigma, USA) was used as a standard. The IAA concentration in the culture supernatant was calculated according to the optical density of the culture, which was measured at $530 \mathrm{~nm}$ with Salkowski's reagent $(12 \mathrm{~g} / \mathrm{L}$ $\mathrm{FeCl}_{3}$ in $7.9 \mathrm{M} \mathrm{H}_{2} \mathrm{SO}_{4}$ ). Each experiment was performed thrice.

\section{Aminocyclopropane-1-carboxylic acid (ACC) deaminase activity}

The selective SMC medium supplemented with ACC was used to isolate bacteria that could utilize ACC as an energy source with $\alpha$-ketobutyrate as a precursor of branched chain amino acids. The ACC deaminase activity in endophytic cells was determined by monitoring the amount of $\alpha$-ketobutyrate generated by the enzymatic hydrolysis of ACC. The endophytes were grown in test tubes containing $10 \mathrm{~mL}$ of the liquid SMC medium (containing per liter: $\mathrm{KH}_{2} \mathrm{PO}_{4}, 0.4 \mathrm{~g} ; \mathrm{K}_{2} \mathrm{HPO}_{4}, 2 \mathrm{~g} ; \mathrm{MgSO}_{4}, 0.2 \mathrm{~g} ; \mathrm{CaCl}_{2}, 0.1 \mathrm{~g}$; $\mathrm{FeSO}_{4}, 5 \mathrm{mg} ; \mathrm{H}_{3} \mathrm{BO}_{3}, 2 \mathrm{mg} ; \mathrm{ZnSO}_{4}, 5 \mathrm{mg} ; \mathrm{Na}_{2} \mathrm{MoO}_{4}, 1 \mathrm{mg}$; $\mathrm{MnSO}_{4}, 3 \mathrm{mg} ; \mathrm{CoSO}_{4}, 1 \mathrm{mg} ; \mathrm{CuSO}_{4}, 1 \mathrm{mg} ; \mathrm{NiSO}_{4}, 1 \mathrm{mg}$; ACC, $0.5 \mathrm{~g} ; \mathrm{NH}_{4} \mathrm{NO}_{3}, 0.3 \mathrm{~g}$; and $\mathrm{H}_{2} \mathrm{O}, 1 \mathrm{~L} ; \mathrm{pH} 6.4$ ) for $24 \mathrm{~h}$ at $30^{\circ} \mathrm{C}$ (Belimov et al., 2005). The cells were harvested by centrifugation at $12000 \mathrm{rpm}$ for $10 \mathrm{~min}$ at room temperature. The cell pellets were washed twice with sterile deionized distilled water and resuspended in $1 \mathrm{~mL}$ of $0.1 \mathrm{M}$ Tris- $\mathrm{HCl}$ buffer. The cells were disrupted by vigorous vortexing with $30 \mu \mathrm{L}$ of toluene. A mixture of $100 \mu \mathrm{L}$ of the cell suspension with $10 \mu \mathrm{L}$ of $0.5 \mathrm{M}$ ACC and $100 \mu \mathrm{L}$ of 
$0.1 \mathrm{M}$ Tris- $\mathrm{HCl}$ buffer ( $\mathrm{pH} 8.5$ ) was incubated for $30 \mathrm{~min}$ at $30^{\circ} \mathrm{C}$ before adding with $1 \mathrm{~mL}$ of $0.56 \mathrm{M} \mathrm{HCl}$. The mixture was centrifuged at $12000 \mathrm{rpm}$ for $5 \mathrm{~min}$ to obtain the supernatant. Subsequently, $400 \mu \mathrm{L}$ of $0.56 \mathrm{M} \mathrm{HCl}$ and $150 \mathrm{~mL}$ of $0.2 \%$ 2,4-dinitrophenylhydrazine in $2 \mathrm{M} \mathrm{HCl}$ were added to $500 \mu \mathrm{L}$ of the supernatant. The mixture was incubated for $30 \mathrm{~min}$ at $30^{\circ} \mathrm{C}$ before adding $1 \mathrm{~mL}$ of $2 \mathrm{M}$ $\mathrm{NaOH}$. The amount of $\alpha$-ketobutyrate was measured by determining the optical density at $600 \mathrm{~nm}$ with mixtures without the cell suspension or ACC as the controls.

\section{Cellulase and pectinase activity}

The activities of cellulase and pectinase were assayed on indicator plates. For the cellulase assay, nitrogenfreebase (NFB) plates supplemented with $0.2 \%$ carboxymethyl cellulose and $0.5 \%$ tryptone were spotted with bacterial cells. After incubation for $48 \mathrm{~h}$ at $30{ }^{\circ} \mathrm{C}$, the plates were coated with a Congo Red $(1 \mathrm{mg} / \mathrm{mL})$ solution for $30 \mathrm{~min}$. The excess stain was discarded, and the agar was destained with $1 \mathrm{M}$ of a $\mathrm{NaCl}$ solution. Plates were kept overnight at $4{ }^{\circ} \mathrm{C}$ and examined on the following day for clearing zones around the points of inoculation.

For the pectinase assay, the bacterial isolates were spotted on NA medium supplemented with $0.5 \%$ pectin, and the plates were incubated at $30^{\circ} \mathrm{C}$. On the fifth day of incubation, a $2 \%$ cetyltrimethyl ammonium bromide (CTAB) solution was added to the plate surface for $30 \mathrm{~min}$ and then discarded. The plates were washed with $1 \mathrm{M} \mathrm{NaCl}$ to visualize the zone around the bacterial growth (Ma et al., 2011).

\section{In vitro detection of antifungal activity}

The interaction of endophytes with pathogenic fungi (F. oxysporum, M. grisea, and A. alternata) was performed via the point inoculation method as previously described (Zhao et al., 2011). Briefly, a small block of agar with fungal growth was cut from potato dextrose agar (PDA) plates (extract of $200 \mathrm{~g}$ potato with $20 \mathrm{~g}$ glucose, $18 \mathrm{~g}$ agar, and $1 \mathrm{~L}$ distilled water) by a sterile puncher $(\varnothing=4 \mathrm{~mm})$. Each block was placed in the center of a fresh PDA plate. Test strains were spot-inoculated on the edge of PDA plate (approximately $25 \mathrm{~mm}$ from the center), incubated at $28 \pm 2{ }^{\circ} \mathrm{C}$ for $7 \mathrm{~d}$, and observed for zones of inhibition, with fungal mycelia cultivated for $7 \mathrm{~d}$ without spot inoculation as control (Geetha et al., 2008). Experiments were performed in triplicate for each bacterial isolate.

\section{Microscopy of fungal mycelia}

The morphological changes caused by endophytes on the mycelia of each pathogenic fungal species after culturing for $4 \mathrm{~d}$ on PDA plates were directly examined, photographed under an optical fluorescence microscope (BX50 Olympus; under 200x magnification), and compared with the structures of the control groups.

\section{Effects of endophyte inoculation on plant growth}

Wheat seeds (Triticum aestivum cv. 'Zhoumai 18', a national authorized wheat variety of China) were surface sterilized with $100 \%$ alcohol for $1 \mathrm{~min}, 5 \%$ sodium hypochlorite for $3 \mathrm{~min}$, and finally rinsed six times with sterile distilled water. Surface-sterilized seeds were allowed to germinate axenically in Petri dishes filled with moist filter paper at $28^{\circ} \mathrm{C}$. The surface-sterilized seeds were immersed for $3 \mathrm{~h}$ in a thick suspension of the exponential phase bacteria (approximately $10^{9}-10^{10} \mathrm{cfu} / \mathrm{mL}$ ) cultured in $5 \mathrm{~mL}$ of YM broth. The germinated seeds were grown in pots filled with sterilized vermiculite, which was moistened with sterile water, as described by Vincent (1970). Seeds were cultured under greenhouse conditions programmed for a $14 \mathrm{~h} / \mathrm{d}$ photoperiod at a constant temperature of $28{ }^{\circ} \mathrm{C}$ during the day and $20{ }^{\circ} \mathrm{C}$ at night at approximately $50 \%$ relative humidity. All pot experiments were incubated with isolates $122,124,130,132,135$, or 170 in three repetitions with 30 seedlings per pot. Seedlings without bacteria were used as the controls. The wheat plants were harvested after 7 weeks when seedling roots were well developed. Parameters such as the fresh weight, dry weight, shoot length, root length, and the chlorophyll content of experimental plants were measured and compared with those of the control plants (plants that were not inoculated with endophyte).

\section{Estimation of chlorophyll content}

The greenest leaves were collected from 20-day-old wheat plants without the dry leaves, plant diseases, and insect pests and were then kept in the dark. A total of 90 plants were used in the replicates, and 3 repetitions were performed. From each plant, three leaves were collected, cut into smaller pieces, and mixed. Subsequently, $1 \mathrm{~g}$ of leaf tissue was crushed in a mixture of ethanol and acetone $(\mathrm{v} / \mathrm{v}$, 1:1) and maintained at $40{ }^{\circ} \mathrm{C}$ for $24 \mathrm{~h}$. The chlorophyll content was spectrophotometrically measured with the specific absorption coefficients for chlorophyll $\mathrm{a}$ and $\mathrm{b}$ at 645 and $663 \mathrm{~nm}$, respectively. The chlorophyll content was calculated according to Geetha et al. (2008), with the mixture of ethanol and acetone as the control.

\section{Identification of endophytic bacterial strains}

\section{Strain morphology, physiological characteristics, and biochemical tests}

The physiological and biochemical characteristics of our isolated strains were determined according to Bergey's Manual of Determinative Bacteriology (VIIIth edition). The main assays were: catalase activity; V-P test; growth in Luria-Bertani broth (pH 5.0) with $0 \%, 2 \%, 5 \%, 7 \%$, and $10 \%$ of $\mathrm{NaCl}$ at $4{ }^{\circ} \mathrm{C}, 10^{\circ} \mathrm{C}, 30^{\circ} \mathrm{C}, 40{ }^{\circ} \mathrm{C}$, and $50^{\circ} \mathrm{C}$; acid production from D-GLUCOSE, D-arabinose, xylose, and D-mannitol; starch hydrolysis; citrate utilization; nitrate reduction; phenylalanine deamination; and casein decomposition. Gram staining, spore production, cellular size, cell shape, and colony characteristics were also examined. 


\section{Sequencing and phylogenetic analysis}

The phylogeny of the 16S rRNA genes has been used as one of the main criteria for differentiating species, genera, and higher taxa in current bacterial taxonomy. To identify the potential endophytic bacteria, total genomic DNA was extracted from the isolates as previously described (Moulin et al., 2004). The 16S rRNA gene was selectively amplified from genomic DNA by PCR with the universal forward primer P1 (5'-CGGGATCCAGAGTTTGATCC TGGCTCAGAACGAACGCT-3') and reverse primer P6 (5'-CGGGATCCTACGGCTACCTTGTTACGACTTCA CCCC-3'), which corresponded to the positions 8-37 bp and 1479-1506 bp, respectively, in the Escherichia coli $16 \mathrm{~S}$ rRNA gene (van Berkum et al., 1996). An aliquot of PCR products of isolates was directly sequenced by the Sangon Biotech (Shanghai) Co., Ltd. with the same primers mentioned above. The acquired and related sequences were matched with the ClustalX 1.81 software and manually corrected with Bioedit 4.8.4. A phylogenetic tree was constructed with the Jukes-Cantor model and the neighbor-joining method (Saitou et al., 1987) by the TREECON software package (van de Peer et al., 1997). The computation of the similarity of each strain tested was performed by the DNAMAN application (version 6.0.3.40; Lynnon Corporation). The obtained 16S rRNA gene sequences were deposited in the NCBI GenBank (http://www.ncbi.nlm.nih.gov/) under the accession numbers KC208613 through KC208618.

\section{Statistical analysis}

Data on the density of endophytic bacteria in different tissues of Lonicera japonica, growth promotion, and endophytic inoculation experiments were treated with ANOVA (analysis of variance), and mean comparisons were performed with Tukey's test $(\mathrm{p}=0.05)$. Regression analysis was performed with the IBM SPSS 17.0 package (by the Data Theory Scaling System Group, Faculty of Social and Behavioral Sciences, Leiden University, The Netherlands).

\section{Results}

\section{Isolation of endophytic bacteria from $L$. japonica}

Endophytic bacteria (48 strains) with different colony morphology (e.g., shape, size, and color) were isolated from the healthy root, stem, and leaf tissues of L. japonica plants. By contrast, no colonies appeared on the NA plates upon incubation at $28^{\circ} \mathrm{C}$ for $2 \mathrm{~d}$ to $3 \mathrm{~d}$, either by rolling over with the sterilized surface portions of this medicinal plant or plating aliquots of water from final rinse solutions, thereby indicating successful surface sterilization. The amount of endophytic bacteria significantly varied between the different tissues, as follows: $3.62 \times 10^{4} \mathrm{cfu} / \mathrm{g}$ in roots, $0.88 \times 10^{4} \mathrm{cfu} / \mathrm{g}$ in stems, and $2.73 \times 10^{4} \mathrm{cfu} / \mathrm{g}$ in leaves (Table 1). No significant differences were observed in the bacterial density between the same tissues among different plants from all four plantation locations $(p=0.05)$.

\section{Characterization of endophytic bacteria for factors with plant growth-promoting potential}

All 48 strains were studied for their siderophore production. Six of these strains showed remarkable performance as evidenced by the orange halo around the colony. The color change is attributed to iron removal by the bacteria from the blue CAS-Fe (III) complex in the CAS agar medium with the dark blue background. Only 5 of the 6 strains except strain 132 produced a siderophore concentration in the range of $1.8-87.2 \mathrm{mg} / \mathrm{L}$ for catecholate and $0.90-76.3 \mathrm{mg} / \mathrm{L}$ for hydroxymate (Table 2 ) in the quantitative analysis. Strains 122 and 124 showed the most significant siderophore production after $24 \mathrm{~h}$ of incubation.

The phosphate solubilization potential was studied for all 48 isolates, only 6 isolates showed a zone of phosphate solubilization on the Pikovskayas agar medium with tricalcium phosphate. These 6 strains were further quantified for phosphate solubilization in a liquid medium; 4 of which were within the range of 1.87-45.6 mg/L (Table 2). Isolated strain 124 had the highest level of phosphate solubilization, whereas isolates 135 and 170 showed levels that were under the detection limit.

IAA production was measured for all the 48 endophytic bacteria in the range of $11.5-49.2 \mathrm{mg} / \mathrm{L}$ after $72 \mathrm{~h}$ of

Table 1 - Density of endophytic bacteria isolated from different tissues of L. japonica (x $\left.10^{4} \mathrm{cfu} / \mathrm{g}\right)$.

\begin{tabular}{lccc}
\hline Origin sites & Roots & Stems & Leaves \\
\hline Shangqiu, Henan Province & $3.56 \pm 0.0038^{\mathrm{a}, \S}$ & $0.87 \pm 0.0048^{\mathrm{a}}$ & $0.96 \pm 0.0089^{\mathrm{b}}$ \\
Huaxian, Henan Province & $3.89 \pm 0.0038^{\mathrm{b}}$ & $0.83 \pm 0.0060^{\mathrm{c}}$ & $2.61 \pm 0.0029^{\mathrm{b}}$ \\
Pingyi, Shangdong Province & $3.67 \pm 0.0092^{\mathrm{c}}$ & $0.86 \pm 0.0021^{\mathrm{a}}$ & $2.87 \pm 0.0062^{\mathrm{c}}$ \\
Juye, Shangdong Province & $3.37 \pm 0.0142^{\mathrm{d}}$ & $0.88 \pm 0.0055$ & $2.45 \pm 0.0092^{\mathrm{d}}$ \\
Mean & $3.62 \pm 0.0078$ & $2.73 \pm 0.0059$ & \\
\hline
\end{tabular}

Notes: Data are the mean of three samples. \pm represents the standard errors of the mean.

${ }^{\S}$ The same letter indicates no significant differences between treatments at 0.05 levels. 
Table 2 - PGPC of endophytic bacteria.

\begin{tabular}{|c|c|c|c|c|c|c|c|}
\hline Strains & $\begin{array}{l}\text { Sid. (C) } \\
(\mathrm{mg} / \mathrm{L})^{*}\end{array}$ & $\begin{array}{l}\text { Sid. (H) } \\
(\mathrm{mg} / \mathrm{L})\end{array}$ & $\begin{array}{l}\text { Pho. } \\
\text { (mg/L) }\end{array}$ & $\begin{array}{l}\text { IAA production } \\
(\mathrm{mg} / \mathrm{L})\end{array}$ & $\begin{array}{l}\text { ACC deaminase } \\
(\mathrm{nmol} / \mathrm{mg} / \mathrm{h})\end{array}$ & $\begin{array}{l}\text { Cellulase activity } \\
\text { (D/d) }\end{array}$ & $\begin{array}{l}\text { Pectinase activity } \\
\text { (D/d) }\end{array}$ \\
\hline 122 & $61.6 \pm 0.17 \mathrm{a}^{\S}$ & $76.3 \pm 0.56 \mathrm{a}$ & $35.3 \pm 0.26 a$ & $18.3 \pm 0.12 \mathrm{a}$ & $45.2 \pm 0.36 \mathrm{a}$ & $1.20 \pm 0.08 \mathrm{a}$ & $1.34 \pm 0.01 \mathrm{a}$ \\
\hline 124 & $87.2 \pm 0.36 b$ & $56.1 \pm 0.26 b$ & $45.6 \pm 0.46 b$ & $11.5 \pm 0.12 b$ & $47.3 \pm 0.26 b$ & $1.14 \pm 0.05 a$ & $1.20 \pm 0.06 b$ \\
\hline 130 & $41.7 \pm 0.53 c$ & $45.5 \pm 0.53 c$ & $14.9 \pm 0.72 \mathrm{c}$ & $29.3 \pm 0.35 c$ & $35.6 \pm 031 \mathrm{c}$ & $0.56 \pm 0.03 c$ & $0.59 \pm 0.05 c$ \\
\hline 132 & - & - & $1.87 \pm 0.07 \mathrm{~d}$ & $22.9 \pm 0.14 \mathrm{~d}$ & - & $0.76 \pm 0.03 d$ & $0.82 \pm 0.01 \mathrm{~d}$ \\
\hline 135 & $1.8 \pm 0.06 \mathrm{~d}$ & $0.90 \pm 0.09 \mathrm{~d}$ & - & $12.6 \pm 0.17 \mathrm{e}$ & $12.3 \pm 0.39 \mathrm{~d}$ & $1.36 \pm 0.03 b$ & $1.43 \pm 0.02 \mathrm{a}$ \\
\hline 170 & $21.9 \pm 0.36 \mathrm{e}$ & $23.4 \pm 0.26 \mathrm{e}$ & - & $49.2 \pm 0.46 f$ & - & $2.58 \pm 0.06 \mathrm{e}$ & $2.64 \pm 0.04 \mathrm{e}$ \\
\hline Control & / & I & I & - & / & - & - \\
\hline
\end{tabular}

Note: Sid. (C), Siderophore production (Catechol-type); Sid. (H), Siderophore production (Hydroxamate-type); Pho phosphate solubilization; IAA, indoleacetic acid; ACC, 1-aminocyclopropane-1-carboxylic acid, activity (nmol $\alpha$-ketobutyrate/mg biomass/h. D/d indicates the ability to produce siderophores, cellulose, and pectinase. $\mathrm{D}$, diameter of colony and halo; $\mathrm{d}$ - colony diameter.

*Average ( \pm , standard deviation), the data in columns is average values of three repetitions.

${ }^{\S}$ The same letter means no significant differences between treatments at 0.01 level; negative action, blank; control for IAA assay was LB (10 g NaCl/L) without inoculated bacterial suspension under the same incubation condition.

incubation (Table 2). The IAA levels of the strains in the culture supernatant matched their anti-fungal activity. Isolate 170 produced significantly higher IAA levels than the other isolates.

Among the tested 48 isolates, only 4 strains could utilize ACC as the sole carbon source (Table 2), which is an indication of the ACC deaminase activity. Among these 4 strains, strains 124 and 122 were the top two strains that utilize ACC as the sole carbon source. Based on the development of a yellow-color zone on the NFB and NA plates, all six strains exhibited cellulase and pectinase activities, with isolate 170 showing the highest levels (Table 2). The statistical differences between strains were shown in Table 2 in terms of the activities of ACC deaminase, cellulase, and pectinase, as well as phosphate solubilization and IAA/siderophore production.

\section{Detection of in vitro antifungal activity}

The inhibitory activity of the 48 endophytic bacterial strains against pathogenic fungi (M. grisea, $F$. oxysporum, and $A$. alternata) was measured. All six selected strains $(12.5 \%)$ strongly inhibited pathogenic fungi compared with the control. Based on the inhibition of mycelial growth, strain 124 showed the strongest effect against $F$. oxysporum (74.39\%), followed by strain 132 against A. alternata (70.93\%), and strain 130 against $M$. grisea $(73.75 \%)$, respectively (Table 3 ). Compared with the controls, the correlation was positive and significant between the activities of hydrolytic enzymes (cellulose and pectinase) and the inhibition rate of $F$. oxysporum (Figure 1A-C) for each strain tested.

\section{Microscopy of pathogenic fungi mycelia}

Compared with the nearly straight and even mycelia of the control under laboratory condition and cultured on PDA medium for $4 \mathrm{~d}$ (Figure 2A-C; also shown in the Supplementary figure), the colonies of the pathogenic fungi shrunk upon interaction with endophytic bacteria, and their mycelia underwent considerable morphological changes, as follows: becoming coralline (Figure 2Da), fractured (Figure 2Fd, f), swollen, globular, or atrophied (Figure 2Fd-f); forming a bending knot (Figure 2Eb-c); and undergoing autolysis (Figure $2 \mathrm{Fe}$ ).

\section{Wheat growth promotion after endophyte inoculation}

The six bacterial isolates with plant growth-promoting potential and antagonistic activity against pathogenic fungi in vitro were further evaluated because of their effectiveness in promoting wheat growth upon in vivo inoculation. Compared with the control, strain 130 significantly increased its shoot length by $14.57 \%$ (Figure $3 \mathrm{~A}$ ), whereas all six strains promoted root length to a different extent. Root length promotion was more pronounced with strains 130,132 , and $170(10.87 \%, 8.42 \%$, and $10.27 \%$, respectively as shown in Figure 3B). Strains 130 and 135 signifi-

Table 3 - Inhibition of endophytic bacteria by pathogenic fungi.

\begin{tabular}{lccccccc}
\hline Strains & Source & \multicolumn{2}{c}{ F. oxysporum } & \multicolumn{2}{c}{ A. alternata } & \multicolumn{2}{c}{ M. grisea } \\
\hline 122 & Root & 2.9 & $64.63^{*}$ & 4.6 & $46.51^{*}$ & 3.4 & $57.50^{*}$ \\
124 & Root & 2.1 & 74.39 & 5.6 & 34.89 & 2.3 & 71.25 \\
130 & Stem & 6.6 & 19.51 & 3.3 & 61.63 & 2.1 & 73.75 \\
132 & Leaf & 6.5 & 20.73 & 2.5 & 70.93 & 4.2 & 47.50 \\
135 & Root & 3.3 & 59.76 & 3.1 & 63.95 & 4.1 & 48.75 \\
170 & Stem & 2.8 & 65.85 & 3.1 & 63.95 & 2.9 & 63.75 \\
Control & $/$ & 8.2 & 0 & 8.6 & 0 & 8.0 & 0 \\
\hline
\end{tabular}

Notes: Data are the mean of three samples.

Colony diameter, $\mathrm{cm}$.

*Inhibition ratio of pathogenic fungus $(\%)=($ Control colony diameter-treatment colony diameter) 100 / Control colony diameter.

Controls for antifungal activity assays were fungal mycelia cultivated for $7 \mathrm{~d}$ on PDA plates without the tested strains under the same incubation condition. 
cantly increased wheat fresh weight (16.48\% and 15.78\%, Figure 3C) and dry weight (20.07\% and 19.65\%, Figure 3D). Regression analysis (Figure 1A) showed a significant positive correlation between IAA production and increase in root length of the wheat seedlings inoculated with endophytic bacteria.

Compared with the uninoculated control (Figure 4), the chlorophyll content of the endopyhte-inoculated wheat

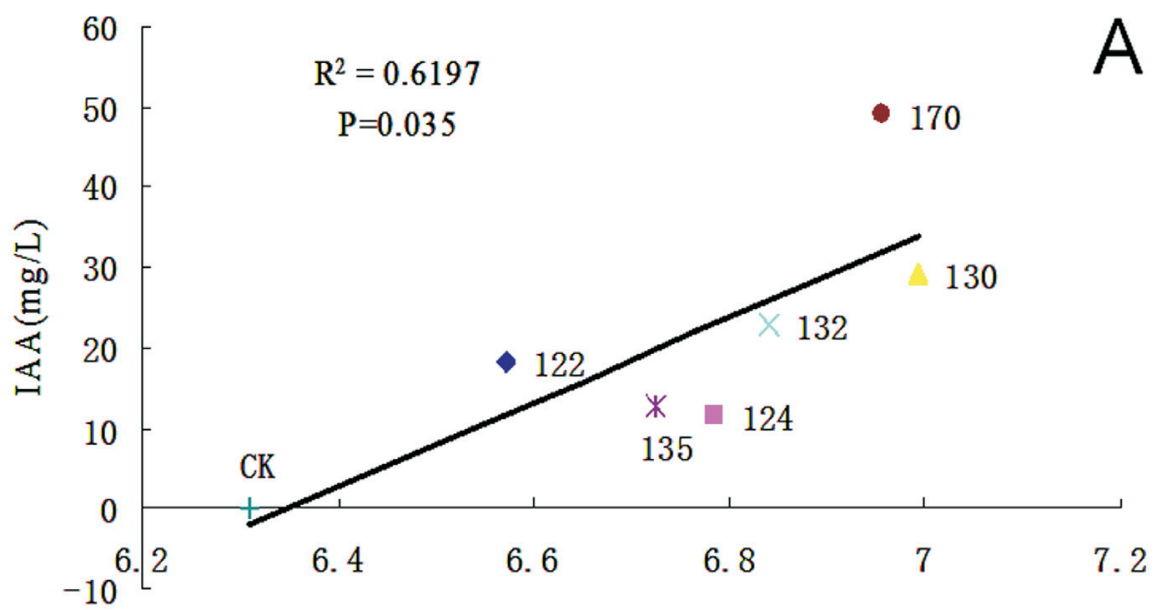

Root length(cm)

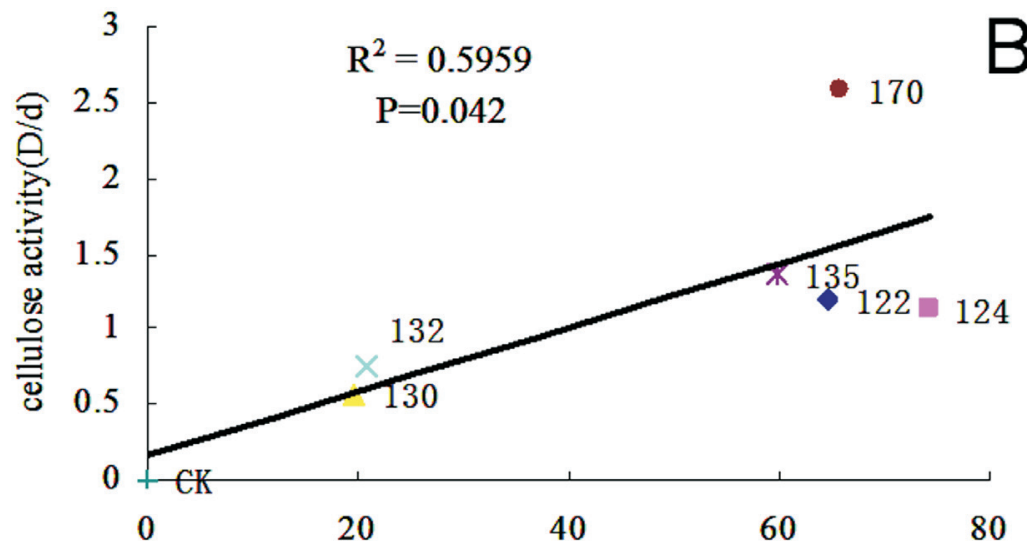

Inhibition rate(\%) to $F$. oxysporum

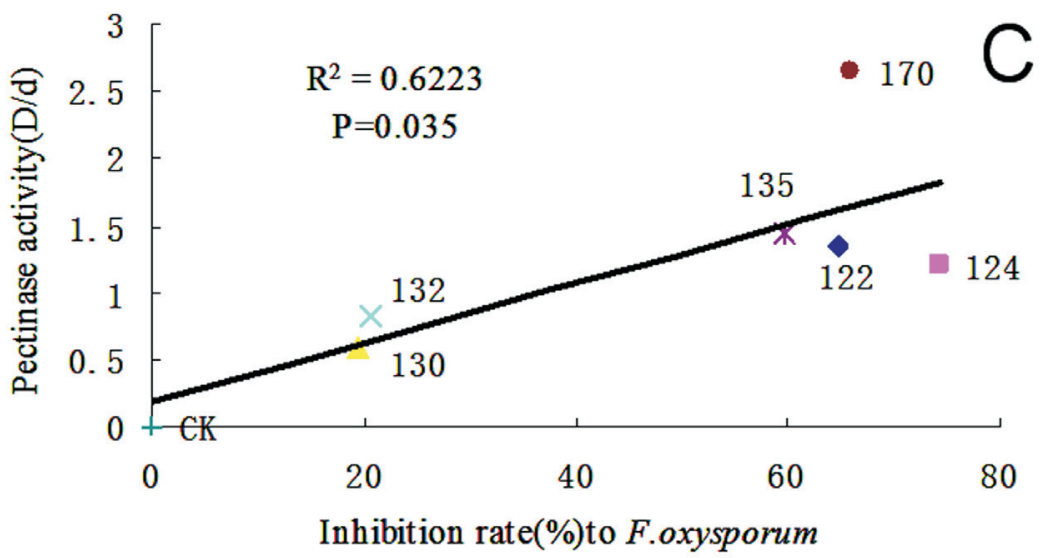

Figure 1 - Regression analysis of the effect of endophytic bacteria on root length and the pathogenic fungus F. oxysporum. (A) Regression analysis of bacterial IAA and root lengths of seedlings inoculated with endopyhtic bacteria. (B) Regression analysis of bacterial cellulase activity and inhibition rate of $F$. oxysporum. (C) Regression analysis of bacterial pectinase activity and inhibition rate of $F$. oxysporum. Names of strains are shown on different data dots. 


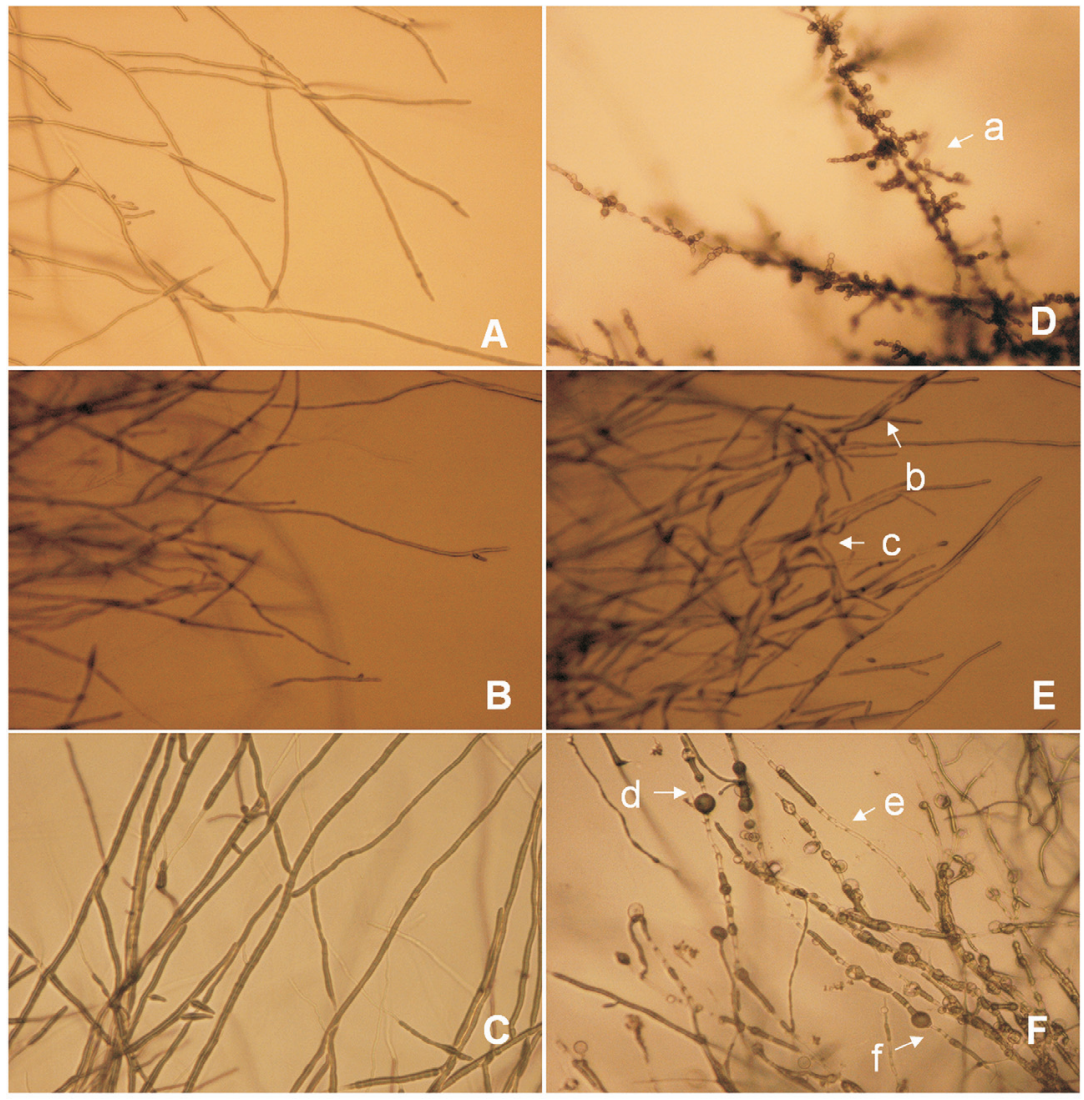

Figure 2 - Morphological changes of the mycelia of plant pathogenic fungi upon interaction with Lonicera japonica endophytes. Images in A, B, and C were representative of normal mycelia of $M$. grisea $\mathrm{MG01}, F$. oxysporum $\mathrm{FO} 02$, and A. alternata AA03. Images in D, E, $\mathrm{F}$ were the atrophy and deformity of M. grisea MG01 mycelia (by strain 130), bending knot of $F$. oxysporum FO02 mycelia (by strain 124), autolysis, fracture, and atrophy of $A$. alternata AA03 mycelia (by strain 132).

increased to a range of $8.4 \%$ to $33.98 \%$, with the strain 130 -treated group showing the highest content (33.98\%). The inoculation of strain 130 induced the highest increase in shoot length, root length, fresh weight, dry weight, and chlorophyll content of wheat.

\section{Identification of the six plant growth-promoting endophytic bacteria}

Physiological and biochemical tests were conducted, including measurements of catalase, V-P test, utilization of carbohydrate, the production of enzymes, growth temperature, salt tolerance, and bacterial morphology (i.e., size, shape, and Gram staining; Supplementary Table 1). Based on these results and the sequencing of 16S rRNA gene and phylogeny analysis (Figure 5 and Table 4), our endophytic isolates belonged to two genera, namely, Bacillus and Paenibacillus. Strains 122 and 130 showed high identity with Paenibacillus and were most closely related to $P$. polymyxa IAM $13419^{\mathrm{T}}(\mathrm{D} 16276)$ and $P$. ehimensis KCTC3748 (AY116665) with $98.7 \%$ and $100 \%$ similarity, respectively. Therefore, a Paenibacillus sub-clade was formed. Strains 170, 124, 132, and 135 had high sequence similarities to B. atrophaeus NRRLNRS-213 ${ }^{\mathrm{T}}$ (EU138516)
(99.6\%), B. megaterium IAM13418 ${ }^{\mathrm{T}}$ (D16273) (99.1\%), and B. subtilis FL (EU221673) with a similarity of $99.6 \%$ and $99.7 \%$.

\section{Discussion}

This work is the first report on the isolation and population density of endophytic bacteria from the medicinal plant $L$. japonica, which is widely planted in the Henan and Shandong provinces in eastern China. As summarized in Table 1, the endophytic bacterial load varied significantly in different tissues, but it remained relatively stable without significant differences in the same tissues of different plants from different planting locations $(p=0.05)$, thereby implying that the prevalence of endophytic bacteria depended on the plant tissues being colonized and the microenvironment they lived in. The endophytic bacterial number in roots is the highest probably because the root soil environment is fairly complex under the effect of both biotic and abiotic factors. Previous studies have reported that the population of endophytic $B$. subtilis E1R-j in roots increases when the bacterial cell number reisolated from the leaf tissue distinctly decreases from the second to fourth 
leaf stage, thereby indicating that $B$. subtilis E1R-j can relocate from the root to the aerial parts of a wheat plant (Liu et $a l ., 2009)$. Our results are in line with those obtained in a recent report (Gao et al., 2012) that endophytic bacterial den- sity varies in different parts of the plant, with the highest value in roots and the lowest value in stems. Similar patterns of bacterial population levels in the root and stem tissues have been widely reported in cabbage (B. subtilis BB),
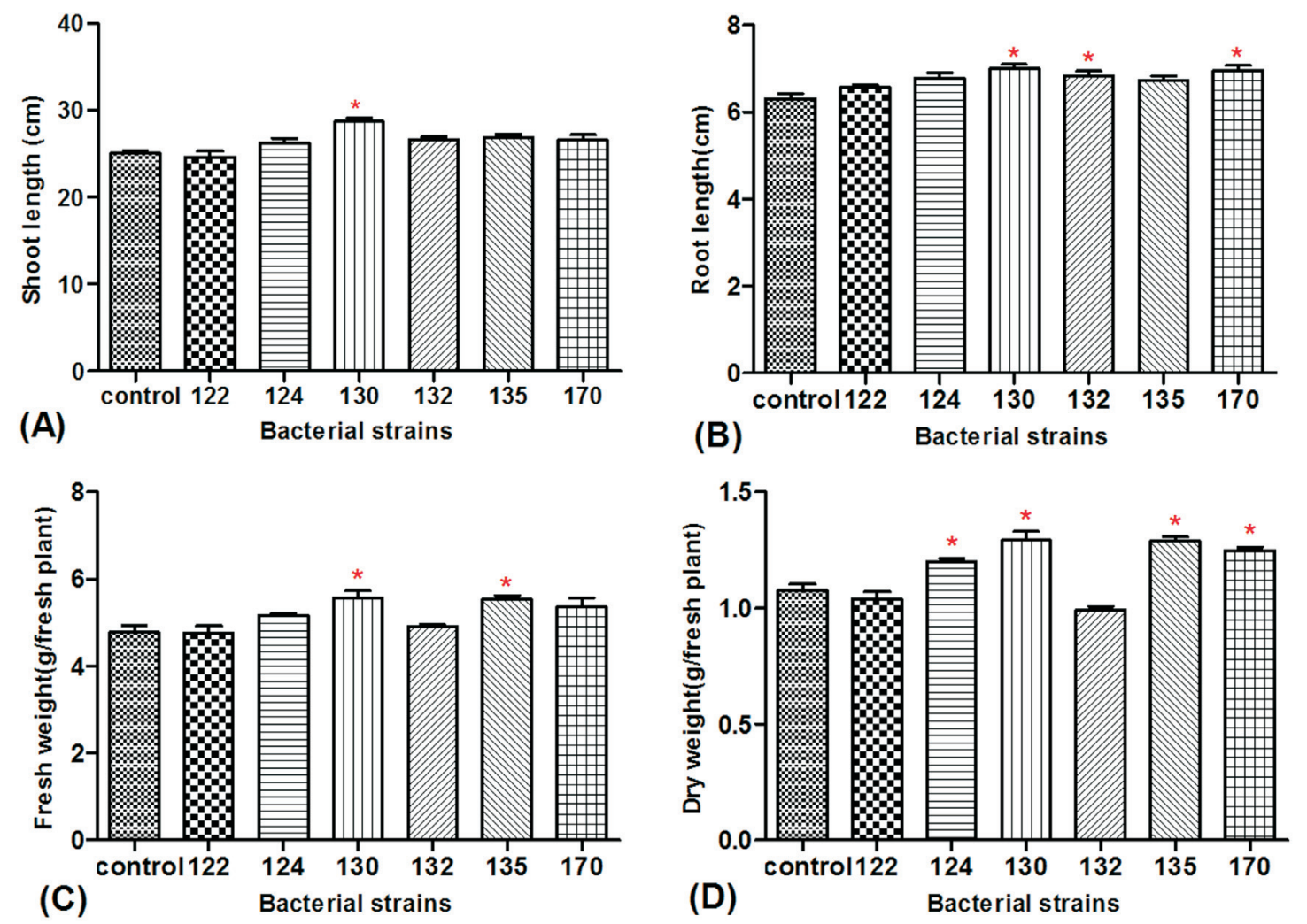

Figure 3 - Effect of six endophytic bacteria on shoot length (A), root length (B), fresh weight (C), and dry weight (D) of wheat seedlings. Each value is the mean of ten replicates. Bars represent the standard deviations of mean. Statistical significance was determined at $\mathrm{p}<0.05$ according to the Tukey's test. The asterisk represents significant differences.

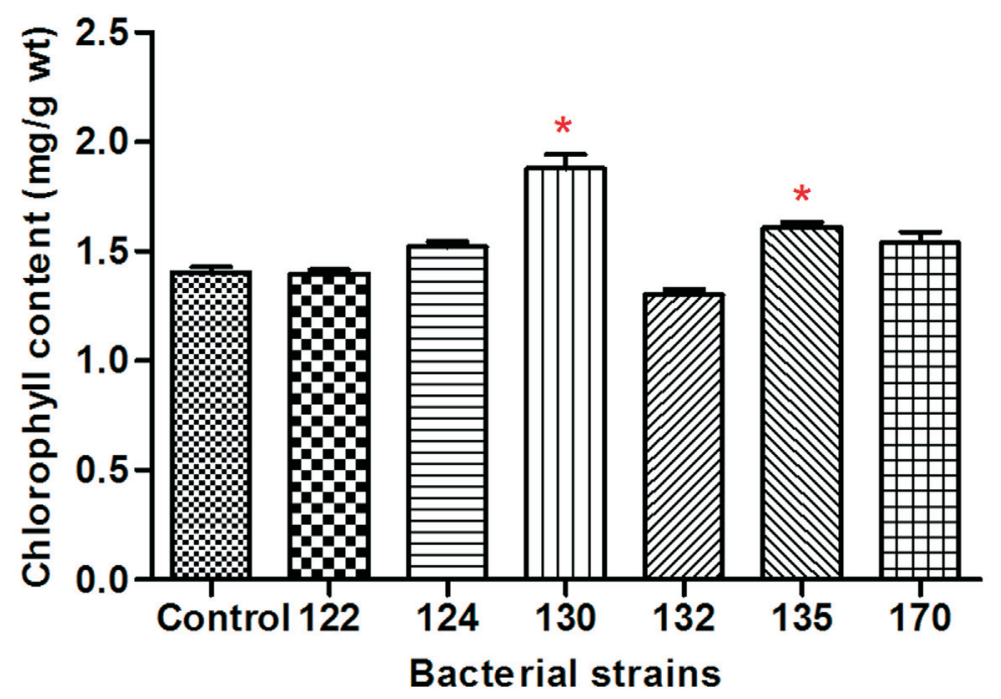

Figure 4 - Effect of six endophytic bacteria on the chlorophyll content of wheat seedlings. Each value is the mean of three replicates. Bars represent the standard deviations of the mean. Statistical significance was determined at $\mathrm{p}<0.05$ according to the Tukey's test. The asterisk represents significant differences. 
cacao (B. subtilis), rose, and crops such as maize, wheat, rice (B. subtilis strain NR-64), soybean, sweet corn, sugar beet, and potato, or in various medicinal plants such as Glycyrrhiza spp., Pinellia ternate, Lycium chinense, Digitalis purpurae, Leonurus heterophyllus, Bletilla striata, Belamcanda chinases, $P$. pedatisecta, and Taxus yunnanensis (Venieraki et al., 2011; Gao et al., 2012; Wulff et al., 2003; Bahig et al., 2012; Li et al., 2012; Miller et al., 2012a; Leite et al., 2013).

Siderophore production could confer competitive advantages in bacteria for colonizing plant tissues, excluding other microorganisms from the same ecological niche

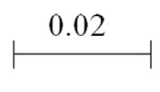

\section{$16 S$ rDNA phylogeny}

\section{「HNSQJYH132 (KC208615) \\ 100 Bacillus subtilis FL (EU221673)}

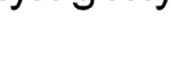

87.
99

98

60

100

100

100

Bacillus cereus ATCC14579 $(\mathrm{AF} 290547)$

$100-$ HNSQJYH124 (KC208614)

Bacillus megaterium IAM13418 $(\mathrm{D} 16273)$

Bacillus amyloliquefaciens NRRLB-14393 ${ }^{\mathrm{T}}$ (EU138458)

100

$100-$ HNSQJYH122 (KC208613)

$100 \quad$ Paenibacillus polymyxa IAM $13419^{\mathrm{T}}(\mathrm{D} 16276)$

100

HNSQJYH130 (KC208617)

Paenibacillus ehimensis KCTC3748 (AY116665)

Agrobacterium tumefaciens IAM13129 (D12784)

Rhizobium etli CFN42 ${ }^{\mathrm{T}}(\mathrm{U} 28916)$

Figure 5 - Neighbor-joining tree based on the alignment of nucleotide sequences of the $16 \mathrm{~S}$ rRNA gene from the tested strains (shown in bold) and reference strains. GenBank accession numbers were placed in parentheses. Bootstrap values greater than $50 \%$ were indicated. Scale bar represents the number of substitutions per site.

Table 4 - Identification and classification of the tested strains

\begin{tabular}{|c|c|c|c|c|}
\hline Strains & Genus affiliation & Accession No. of the $16 \mathrm{~S}$ rDNA sequence & Best closest match & Similarity (\%) \\
\hline 122 & Paenibacillus & KC208613 & Paenibacillus polymyxa IAM $13419^{\mathrm{T}}$ (D16276) & 98.7 \\
\hline 124 & Bacillus & KC208614 & Bacillus megaterium IAM13418 ${ }^{\mathrm{T}}$ (D16273) & 99.1 \\
\hline 130 & Paenibacillus & KC208617 & Paenibacillus ehimensis IFO15659 ${ }^{\mathrm{T}}$ (AB021184) & 100 \\
\hline 132 & Bacillus & KC208615 & Bacillus subtilis FL (EU221673) & 99.6 \\
\hline 135 & Bacillus & KC208616 & Bacillus subtilis FL (EU221673) & 99.7 \\
\hline 170 & Bacillus & KC208618 & Bacillus atrophaeus NRRLNRS-213 ${ }^{\mathrm{T}}$ (EU138516) & 99.6 \\
\hline
\end{tabular}


(Loaces et al., 2011), competing for nutrients, and protecting plant from phytopathogens (Compant et al., 2005). Metagenomic analysis (Sessitsch et al., 2012) revealed that the presence of a high number of genes involved in siderophore production in an endophyte community that colonizes rice roots indicates a strong biocontrol capacity because endophytes compete with other pathogens for iron. Among the 6 endophytic bacteria (3 strains from roots, 2 strains from stems, and 1 strain from leaves; 4 Bacillus and 2 Paenibacillus strains), strains 122 and 124 showed a higher capacity for siderophore production.

Several phosphate-solubilizing microorganisms are able to convert insoluble phosphorus to a soluble form through acidification, secretion of organic acids or protons (Richardson et al., 2009), or chelation and exchange reactions (Hameeda et al., 2008; Bhattacharyya et al., 2012), thereby representing a possible mechanism of direct plant growth promotion under field conditions (Verma et al., 2001). These microorganisms are important for plant nutrition because they increase phosphate uptake and act as biofertilization promoters of wheat crops. Bacillus is reportedly one of the most significant phosphate-solubilizing bacteria (Mehnaz et al., 2006). Four of our six strains are capable of phosphate solubilization. Strains 124 (Bacillus) and 122 (Paenibacillus) showed relatively higher phosphate solubilization than the others, and these strains significantly increased the dry weight and fresh weight of the inoculated wheat, respectively.

In this report, six endophytic strains from the medicinal plant $L$. japonica exhibited inhibitory activity (Table 3 ) against phytopathogenic fungi (F. oxysporum, $M$. grisea, $A$. alternata), which are useful model organisms for studying various aspects of host-pathogen interactions. These pathogens are chosen as test targets in the antifungal activity experiment because of their capacity to cause epiphytic disease and major damage in crops and plants, including $L$. japonica and wheat. Previous works have verified that promoting plant growth and inhibiting phytopathogen growth may involve a large number of bacterial endophytes. A recent report also suggests that the cellulase and pectinase produced by Klebsiella oxytoca GR-3 might play an important role in plant-microbe interactions and the intercellular colonization of roots (Ma et al., 2011). Our findings revealed that all 6 of the selected strains (Bacillus and Paenibacillus) exhibited cellulose and pectinase activities.

Growth-promoting agents can enhance plant growth and have the potential to replace the use of chemical fertilizers, pesticides, and other supplements (Kim et al., 2011; Bhattacharyya et al., 2012). Endophytes that are associated with medicinal plants are of interest as producers of compounds responsible for the observed plant bioactivity with biosynthetic potential (Miller et al., 2012b). This finding is in agreement with our result, i.e., strain 130 induced the largest increase in root length, stem length, flesh weight, dry weight, and the chlorophyll content of wheat in vivo, al- though its in vitro ACC deaminase activity is lower than that of strains 122 and 124 . One explanation for this phenomenon is that strain 130 contains ACC deaminase but its activity was not induced very much in the in vitro study. Alternatively, strain 130 showed a higher IAA production, thereby directly promoting wheat growth via hormonal stimulation. Furthermore, plant growth is the overall result of all growth-promoting molecules produced by root endophytes and ectophytes (Patten et al., 2002).

In summary, our work showed that some of the endophytic bacteria (strains 130,135, and 170) isolated from the medicinal plant $L$. japonica can produce wheat growthpromoting molecules in vitro and increase wheat growth (i.e., root length, stem length, flesh weight, dry weight, and chlorophyll content) in vivo. Therefore, these endophytic bacteria have the potential to be used as plant growthpromoting agents in agriculture to increase crop growth.

\section{Acknowledgments}

This work was supported by projects from the National Science Foundation of China (U1204301), the Henan Provincial Education Department of Science and Technology Research Key Research Project (12A210019), and the Foundation for University Key Teacher by the Ministry of Education of Henan Province (2012GGJS166). The Authors are grateful to Dr. Guihong Yin for providing the wheat seeds (cv. 'Zhoumai18'). We thank Prof. Yi Ren of the Department of Biomedical Sciences, Florida State University College of Medicine, Tallahassee, FL, USA, Dr. Jane Kelly, of the Medical Research Service, RD-33, Department of Veterans Affairs Medical Center, 3710 SW U.S. Veterans Hospital Road, Portland, OR, USA, and an anonymous reviewer from the USA for proofreading and polishing the final draft of our manuscript.

\section{References}

Bahig ED, Salih B, Youssuf G et al. (2012) Characterization of endophytic bacteria associated with rose plant (Rosa damascena trigintipeta) during flowering stage and their plant growth promoting traits. J Plant Interact 7:248-225.

Belimov AA, Hontzeas N, Safronova VI et al. (2005) Cadmiumtolerant plant growth-promoting bacteria associated with the roots of Indian mustard (Brassica juncea L. Czern.). Soil Biol Biochem 37:241-250.

Bhattacharyya PN, Jha DK (2012) Plant growth-promoting rhizobacteria (PGPR): emergence in agriculture. World J Microb Biot 28:1327-1350.

Bianco A, Daffonchio FQ, Lorenzo B et al. (2011) Restructuring of Endophytic Bacterial Communities in Grapevine Yellows-Diseased and Recovered Vitis vinifera L. Plants. Appl Environ Microbiol 77:5018-5022.

Broggi L, González HHL, Resnik S et al. (2007) Alternaria alternata prevalence in cereal grains and soybean seeds from Entre Ríos, Argentina. Rev Iberoam Micol 24:47-51.

Chen Y, Yan F, Chai Y et al. (2013) Biocontrol of tomato wilt disease by Bacillus subtilis isolates from natural environments 
depends on conserved genes mediating biofilm formation. Environ Microbiol 15:916-927.

Compant S, Duffy B, Nowak J et al. (2005) Use of plant growthpromoting bacteria for biocontrol of plant diseases: principles, mechanisms of action, and future prospects. Appl Environ Microb 71:4951-4959.

Deng ZS, Zhao LF, Kong ZY et al. (2011) Diversity of endophytic bacteria within nodules of the Sphaerophysa salsula in different regions of Loess Plateau in China. FEMS Microbiol Ecol 76:463-475.

Fiske CH, Subbarow Y (1925) A colorimetric determination of phosphorus. J Biol Chem 66:375-400.

Gao LL, Chen XL, Jian T et al. (2012) Isolation and identification of endophytic nitrogen-fixing bacteria in rice with antipathogenic functions. J Huazhong Agri University 31:553557.

Geetha R, Falguni S, Anjana JD et al. (2008) Enhanced growth and nodulation of pigeon pea by co-inoculation of Bacillus strains with Rhizobium spp.. Biores Technol 99:4544-4550.

González HHL, Pacin A, Resnik SL et al. (1996) Deoxynivalenol and contaminant mycoflora in freshly harvested Argentinean wheat in 1993. Mycopathologia 135:129-134.

Gordon AS, Weber RP (1951) Colorimetric estimation of indoleacetic acid. Plant Physiol 26:192-195.

Hameeda B, Harini G, Rupela OP et al. (2008) Growth promotion of maize by phosphate-solubilizing bacteria isolated from composts and macrofauna. Microbiol Res 163:234-242.

Inés L, Lucía F, Ana Fernández S (2011) Dynamics, diversity and function of endophytic Siderophore-producing bacteria in rice. Microb Ecol 61:606-618.

Khan Z, Kim SG, Jeon YH et al. (2008) A plant growth promoting Paenibacillus polymyxa strain GBR-1, suppresses root-knot nematode. Biores Technol 99:3016-3023.

Kim YC, Johan L, Brian B et al. (2011) The multifactorial basis for plant health promotion by plant- associated bacteria. Appl Environ Microbiol 77:1548-1555.

Lai KP, Chen SH, Hu MY et al. (2012) Control of postharvest green mold of citrus fruit by application of endophytic Paenibacillus polymyxa strain SG-6. Postharv Biol Technol 69:40-48.

Leite HA, Silva AB, Gomes FP et al. (2013) Bacillus subtilis and Enterobacter cloacae endophytes from healthy Theobroma cacao L. trees can systemically colonize seedlings and promote growth. Appl Microbiol Biotechnol 97:2639-2651.

Li HJ, Li P, Ye WC (2003) Determination of five major iridoid glucosides in Flos Lonicerae by high-performance liquid chromatography coupled with evaporative light scattering detection. J Chromatogr A 1008:167-172.

Li J, Zhang HR, Liu NY et al. (2010) Study on isolation and identification endophytic fungi and antibacterial activity of Flos Lonicerae. Chin J Antibiot 35:236-238.

Li L, Sinkko H, Montonen L et al. (2012) Biogeography of symbiotic and other endophytic bacteria isolated from medicinal Glycyrrhiza species in China. FEMS Microbiol Ecol 79:4668.

Liu B, Qiao HP, Huang LL et al. (2009) Biological control of take-all in wheat by endophytic Bacillus subtilis E1R-j and potential mode of action. Biol Control 49:277-285.

Loaces I, Lucía F, Ana FS (2011) Dynamics, diversity and function of endophytic siderophore-producing bacteria in rice. Microb Ecol 61:606-618.
Ma Y, Mani R, Luo YM et al. (2011) Inoculation of endophytic bacteria on host and non-host plants-effects on plant growth and Ni uptake. J Hazard Mater 195:230-237.

María SO, María ES, María MR et al. (2013) Toxigenic profile and AFLP variability of Alternaria alternata and Alternaria infectoria occurring on wheat. Braz J Microbiol 44:447-455.

Mehnaz S, Lazarovits G (2006) Inoculation effects of Pseudomonas putida, Gluconacetobacter azotocaptans, and Azospirillum lipoferum on corn plant growth under greenhouse conditions. Microb Ecol 51:326-335.

Miller KI, Qing C, Sze DM et al. (2012a) Culturable endophytes of medicinal plants and the genetic basis for their bioactivity. Microb Ecol 64:431-449.

Miller KI, Qing C, Sze DMY et al. (2012b) Investigation of the biosynthetic potential of endophytes in traditional Chinese anticancer herbs. Plos One 7:e35953.

Moulin L, Béna G, Boivin-Masson C et al. (2004) Phylogenetic analyses of symbiotic nodulation genes support vertical and lateral gene co-transfer within the Bradyrhizobium genus. Mol Phylogenet Evol 30:720-732.

Mphprc (2000) Pharmacopoeia of the People's Republic of China. Chemical Industry Press, Beijing, 177 p.

Patten CL, Glick BR (2002) The role of bacterial indoleacetic acid in the development of the host plant root system. Appl Environ Microbiol 68:3795-3801.

Ramirez ML, Sturm ME, Oviedo MS et al. (2005) Alternaria species isolated from wheat in Argentina. Proceeding of MycoGlobe: Reducing Impact of Mycotoxins in Tropical Agriculture. Acra, Ghana, pp 35.

Raza W, Yang XM, Wu HS et al. (2009) Isolation and characterization of fusaricidin-type compound-producing strain of Paenibacillu polymyxa SQR-21 active against Fusarium oxysporum f. sp. nevium. Eur J Plant Pathol 125:471-483.

Richardson AE, Barea JM, McNeill AM et al. (2009) Acquisition of phosphorus and nitrogen in the rhizosphere and plant growth promotion by microorganisms. Plant Soil 321:305339.

Saitou N, Nei M (1987) The neighbor-joining method: a new method for reconstructing phylogenetic trees. Mol Biol Evol 4:406-425.

Schwyn B, Neilands JB (1987) Universal chemical assay for the detection and determination of siderophores. Anal Biochem 160:47-56.

Sessitsch A, Hardoim PJ, Döring WA et al. (2012) Functional characteristics of an endophyte community colonizing rice roots as revealed by metagenomic analysis. MPMI 25:2836.

Sundara-Rao WVB, Sinha MK (1963) Phosphate dissolving microorganisms in the soil and rhizosphere. Indian J Agr Sci $33: 272-278$

Van Berkum P, Beyene D, Eardly BD (1996) Phylogenetic relationships among Rhizobium species nodulating the common bean (Phaseolus vulgaris L.). Int J Syst Evol Microbiol 46:240-244

Van de Peer, Wachter YDR (1997) Construction of evolutionary distance trees with TREECON for Windows: accounting for variation in nucleotide substitution rate among sites. Comput Appl Biosci 13:227-230.

Venieraki A, Dimou M, Pergalis P et al. (2011) The genetic diversity of culturable nitrogen-fixing bacteria in the rhizosphere of wheat. Microb Ecol 61:277-285. 
Verma SC, Ladha JK, Tripathi AK (2001) Evaluation of plant growth promoting and colonization ability of endophytic diazotrophs from deep water rice. J Biotechnol 91:127-141.

Vincent JM (1970) The cultivation, isolation and maintenance of Rhizobia. A Manual for the practical study of the rootnodule bacteria international biological programme handbook. Blackwell Scientific, Oxford, pp 1-13.

Wu L (2007) Effect of chlorogenic acid on antioxidant activity of Flos Lonicerae extracts. J Zhejiang Univ Sci B 8:673-679.

Wulff EG, van Vuurde JWL, Hockenhull J (2003) The ability of the biological control agent Bacillus subtilis, strain BB, to colonise vegetable brassicas endophytically following seed inoculation. Plant and Soil 255:463-474.

Xu YJ, Zhao LF, Dai M et al. (2013) Isolation and characteristic of endophytic bacteria in medicinal plant Flos Lonicerae. Guandong Agr Sci 40:121-124.
Zhao LF, Xu YJ, Sun R et al. (2011) Identification and characterization of the endophytic plant growth prompter Bacillus cereus strain MQ23 isolated from Sophora alopecuroides root nodules. Braz J Microbiol 42:567-575.

\section{Supplementary Material}

Figure S1. Antagonistic activity of endophytes against phytopathogenic fungi after $3 \mathrm{~d}$. (A) Inhibition of $M$. grisea MG01 by endophyte strain 130; (B0 inhibition of $F$. oxysporum FO02 by endophyte strain 124; C. inhibition of A. alternata AA03 by endophyte strain 132. A', B', and C' were control pathogenic fungusfungal colonies without endophytes.

Table S1. A Physiological and biochemical test results and cell characteristics of strains 122, 124, 130, 132, 135, and 170 .

Associate Editor: Lara Durães Sette

All the content of the journal, except where otherwise noted, is licensed under a Creative Commons License CC BY-NC. 